\title{
How to Conquer One's Weaker Self: Does Autonomy Affordance Increase Goal Performance and Well-being?
}

\author{
Henner Gimpel \\ FIM Research Center, \\ University of Augsburg, and \\ Project Group Business \& \\ Information Systems Engineering \\ of the Fraunhofer FIT \\ henner.gimpel@fim-rc.de
}

\author{
Niclas Nüske \\ FIM Research Center, University of \\ Applied Sciences Augsburg, and \\ Project Group Business \& \\ Information Systems Engineering \\ of the Fraunhofer FIT \\ niclas.nueske@fim-rc.de
}

\author{
Christian Regal \\ FIM Research Center, \\ University of Augsburg, and \\ Project Group Business \& \\ Information Systems Engineering \\ of the Fraunhofer FIT \\ christian.regal@fim-rc.de
}

\begin{abstract}
Positive self-tracking technologies support users in conducting personal analytics and aim to foster their users' goal attainment and well-being. A driver for these two is the experience of autonomy which can be afforded by self-tracking IS. In this paper, we examine the influence of autonomy affordance provided by self-tracking IS as well as its actualization on goal performance and well-being. For this purpose, empirical data was collected in a field experiment using a self-developed mobile self-tracking application. The results of a path analysis indicate that the mere provision of autonomy affordance is positively linked to well-being and that its actualization positively affects goal performance, in turn improving well-being. Contributing to design knowledge in positive computing and self-tracking IS as well as Affordance Theory, we find that the design of self-tracking IS should provide autonomy affordance to further both their users' goal performance and well-being.
\end{abstract}

\section{Introduction}

Increasing digitalization is changing our private and job life. This affects, for example, the way we work, how we communicate, but also how we learn and evolve. As a result, personal analytics is one of the major new trends included in Gartner Hype Cycles for Emerging Technologies [36]. Personal analytics describes an individual's use of data for purposes such as healthcare and self-actualization. It mostly makes use of digital technologies for real-time measurement of data regarding goals, activities, and behaviors [20]. Positive technologies, as a subset of such digital selftracking technologies - aim to support users in achieving their goals [4], the realization of which results in improved well-being $[12,15]$, another core aim of positive technologies.

A crucial process for attaining a goal is the monitoring of the goal-pursuing activities which helps to ensure that initially-set goals are translated into action [12]. A meta-analysis on monitoring goal progress revealed that progress monitoring has more substantial effects on goal attainment when the progress is recorded and the frequency of progress monitoring is increased [12]. Digital self-tracking technologies can support this by providing capabilities to monitor the user's goal progress. So-called habit trackers, mostly available as mobile applications, enable users to set goals and easily keep track of the goal progress by providing a stimulating but straightforward design. Loop Habit Tracker, for example, is one of the best-rated habit trackers in the Google Play Store and provides users with a simple and easy-to-use interface to keep track of their goals.

However, it requires more than an easy-to-use interface so that a habit tracker is used continuously $[6,26]$. Imagine coming home late from work, exhausted from the day. Your self-tracking IS tells you that you still have a run scheduled for today according to a plan that you committed to a few weeks ago. If you do not run today, you will not reach your goal and feel bad for it. You might even question your motives for committing to your plan in the first place. Even if you do run today, it may bring you closer to your goal, but it is not clear whether this will increase your wellbeing. What if your plan and your self-tracking IS allowed you to easily adapt your behavior to the circumstances? After all, you could have moved the run to a rest day scheduled for yesterday or tomorrow. It might help here if habit trackers not only allowed freedom in the planning stages but also during the execution of the plan and progress tracking. 
Furthermore, providing the possibility to adapt the technology and, in particular, the pre-determined plans to meet the user's needs would also foster the continuous usage of the habit tracker $[6,26]$. This means that affording users with certain kinds of autonomy while they work towards their goals, which could have a tremendous effect on the success in pursuing goals as well as well-being $[25,30]$. Such a possibility for autonomy is an affordance. An affordance, in general, is defined as "the possibility for goal-oriented actions afforded to specific user groups by technical objects" [23]. We define an autonomy affordance in the context of digital self-tracking as the possibility to continuously adapt the self-tracking information system (IS) and its comprised information to the user's needs. However, most habit trackers mainly focus on an appealing design or a wide selection of features [38] and neglect the potential positive effects of providing autonomy affordance by making a self-tracking IS more adaptable to the user's needs [26]. From this we derive the following research question:

What is the influence of the provision of enhanced autonomy affordance and its actualization in digital self-tracking IS on goal performance and well-being?

In the following, we describe the essential components of our research question which are concepts that are discussed in various areas of research such as the IS system design, self-tracking, positive computing, and psychology. Based on this, we derive hypotheses from explaining the relationship between our constructs. Subsequently, we describe the development and deployment of the self-developed self-tracking IS for the data collection. After the presentation and discussion of our results, we cover our work's theoretical and practical implications, its limitations, and the resulting need for further research.

\section{Theoretical Background}

Self-tracking IS can be employed to increase individuals' well-being and support them, for example, in achieving their goals. These IS are designed with the aim of "improving the quality of our personal experience with the goal of increasing wellness and generating strengths and resilience in individuals, organizations, and society" [4]. For this purpose, various types of data (e.g., biological, physical, behavioral, or environmental information) are collected within the IS, both manually or by using digital technologies such as mobile devices and sensors. This enables an increasingly detailed realtime measurement of data regarding activities and behaviors and their analysis and distribution [21].
A goal can be defined as "a cognitive representation of a future object that an organism is committed to approach or avoid" [8]. In the context of self-tracking, goals like doing sports, getting up early, or eating in specific ways may refer to behaviors which the individual aims to transform into habits. "Habits are learned dispositions to repeat past responses" [37], i.e., behaviors or actions which are automatically triggered by cues in the individual's context. Goals play an essential role in habit formation as they provide the trigger to perform the first repetitions of the desired behavior which then becomes automatic [37]. Goals can furthermore be distinguished regarding their time horizon. Long-term goals take more than five years, medium-term goals take one to five years [32], and short-term goals take up to one year to achieve [3].

Once a goal is set, there are multiple terms for describing the path to its fulfillment as well as its fulfillment itself. In a broad literature review related to goal progress, Klug and Maier [15] include studies assessing goal progress, goal pursuit, goal attainment, and goal achievement, and subsume the terms under goal success. In a literature review related to monitoring goal progress, Harkin et al. [12] distinguish between behavioral goal performance and goal attainment. As self-tracking centers on gathering and analyzing data about regular habits, behaviors, and feelings [20], and as the behavior of individuals is the basis for any determination of goal success, we will use the term goal performance to describe the process of pursuing and possibly accomplishing a goal.

A major driver of goal performance is motivation. According to Ryan and Deci's Organismic Integration Theory, motivation can be subdivided concerning the degree of internalization, which is the extent to which an individual incorporates a value or a behavior's regulation into the self [30]. In three studies and a meta-analysis, Koestner et al. [17] found higher internalization to be substantially related to goal progress, whereas lower internalization was not.

Goal performance has furthermore been linked to enhanced well-being in various studies [31]. The psychological literature regarding well-being can be divided into two main fields: subjective well-being and psychological well-being [11]. To determine the overall flourishing of an individual, both need to be considered [14]. Subjective well-being takes a hedonic perspective, i.e., it focuses on happiness and positive or negative, temporary feelings. Psychological wellbeing takes an eudemonic view, i.e., it concentrates on self-attainment and meaning [31].

Moreover, according to Ryan and Deci's Selfdetermination Theory, the three basic needs autonomy, competence, and relatedness are crucial for 
promoting well-being [30]. The drivers of autonomy are "a sense of choice, volition, and freedom from excessive external pressure" [30]. Transferred to the context of monitoring goal performance in selftracking IS, users experience autonomy if provided with options to adapt their plans and exercise control regarding their goal-directed behavior.

We take an affordance perspective on the interplay of the provision of these options in selftracking IS and their perception and actualization by the users. A functional affordance, in general, is defined as "the possibility for goal-oriented actions afforded to specific user groups by technical objects". In the context of our work, users of self-tracking IS (user group and technical object) aim to achieve and track progress regarding goal performance (goal). An affordance arises from the relationship between the properties of an object and the abilities of the agent who interacts with it. It is not a property or feature of the object per se [24]. Following Norman [24], an affordance is communicated by signifiers, which refer to "any mark or sound, any perceivable indicator that communicates appropriate behavior to a person". We define and use the term autonomy affordance as the possibility to adapt users' plans for goal-directed behavior, which is enabled by features and communicated by signifiers in a self-tracking IS.

\section{Hypotheses Development}

According to Self-determination Theory, higher levels of autonomy should result in higher levels of well-being [30]. In this study, we focus on the subjective well-being facet as it is more variable over time ([18]; [7]). In contrast to the more stable psychological well-being, we can observe the effects of a manipulation of autonomy affordance on subjective well-being in the course of a field experiment. We hypothesize that an enhancement of autonomy affordance positively affects subjective well-being (H1). This enhancement of autonomy affordance is manifested as the extension of features (and their signifiers) that enable plan adaptations for the goal-directed behavior of self-tracking IS users. An affordance can exist without being actualized [34]. H1 covers the mere offer of enhanced autonomy affordance and its relationship to subjective wellbeing. We suggest that it is enough for users of a selftracking IS to perceive enhanced autonomy affordance by its signifiers to feel more autonomous.

In case that autonomy affordance is actualized, its actualization (a behavior) should self-evidently be contingent on its provision. We thus hypothesize a positive effect of the enhancement of autonomy affordance on its actualization (H2).
As pointed out in $\mathrm{H} 1$, self-tracking IS users should feel more autonomous by simply perceiving enhanced autonomy affordance. Besides, we suppose that the positive effect of the experience of autonomy on subjective well-being in part works via the mediator affordance actualization. We hypothesize that the actualization of autonomy affordance positively influences subjective well-being $(\mathbf{H 3})$.

In a meta-analysis of studies examining choice and its various outcomes, Patall et al. [25] found significant, mainly positive effects of choice on, among others, effort, task performance, and subsequent learning. Other studies as well showed that the satisfaction of the basic need autonomy, among others, was positively related to learning outcomes [1]. Transferred to our context, we hypothesize that the actualization of autonomy affordance positively affects goal performance $(\mathbf{H 4})$.

Goal performance has been linked to well-being in several studies. Brunstein [5] found progress in the achievement of personal goals to predict subjective well-being. Two meta-analyses confirmed the high correlation between successful striving towards longterm goals and subjective well-being $[15,16]$. Steca et al. [32] found a slightly weaker positive influence of short-term goal progress on subjective well-being. We hypothesize goal performance to positively affect subjective well-being (H5).

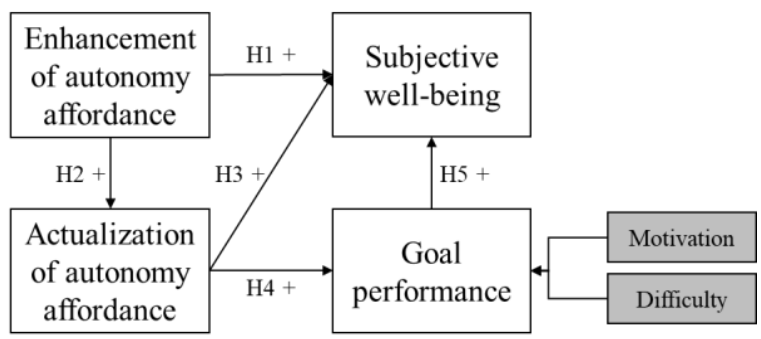

Figure 1. Hypothesized relationships between enhanced autonomy affordance, its actualization, subjective well-being, goal performance, and the control variables

When examining the effect of enhanced autonomy affordance and its actualization on goal performance and well-being in self-tracking IS, two influences external to self-tracking should be controlled: motivation and difficulty. Vansteenkiste et al. [35] showed intrinsic goal-motivation as well as autonomy-supportive environments to have an impact on the performance of students. We cover the latter influence, autonomy-supportive contexts, with our main independent variable, enhanced autonomy affordance. However, we do not yet consider the former influence, motivation. Thus, we include a goal's original motivation as a control variable. 
Lastly, performing well concerning goals that are easy to achieve seems to be more likely than concerning harder or more complicated goals. As a second control variable of goal performance, we, therefore, include goal difficulty in our model. Figure 1 outlines the proposed relationships between our four focal constructs and the two control variables.

\section{Methodology}

The empirical test of the hypothesized relationships bases on a field experiment manipulating autonomy affordance to measure the effects. As no self-tracking IS allowing to manipulate autonomy affordance was readily available, we designed, developed, and deployed a mobile application for tracking the goal performance of individuals regarding self-set goals. Participants were randomly assigned to either of two treatments differing in the level of autonomy affordance. Data was gathered automatically by the app.

\subsection{The Measurement Instrument}

The mobile application developed to allow for testing our hypotheses was available for the operating systems Android and iOS. The app enabled users to enter goals that they wanted to achieve or habits that they wanted to integrate into their life. On one tab ("GOALS"), users could create and manage goals. To create a goal, users entered a title or selected one from a list of 90 recommendations from different categories such as sports and learning. Users were then asked to indicate the weekdays on which they would like to conduct activities pursuing the new goal. Users were asked to state the subjective difficulty of reaching the new goal and to select the most suitable motivation for the new goal from a list. Users were also able to add further goals, edit, or delete existing goals.

In a second tab ("JOURNAL"), users could view their goal journal. The view provided a list divided into separate days which were displayed in the headline of each section, starting one week before the current day and ending three weeks after. Under each headline, all goal-pursuing activities of all goals which were planned for that day were listed and identified via the goal title. For each of these activities, users could log their progress by clicking on a check (done) or on a cross (not done). In each case, they were asked to indicate their current feeling on a scale of five emoji. Logging and unlogging activities were enabled for the current day and all days before.

For illustrations of the measurement instrument, please see Figure 2 and the online appendix.

\subsection{Manipulating Autonomy Affordance}

We created two versions of the app which differed regarding the level of autonomy affordance. We manipulated autonomy affordance by including or excluding a total of three features and three autonomy affordance signifiers (see Figure 2 and the online appendix for illustrations) which were derived from an analysis of commercial habit-tracking apps and user interviews in the app design stage:

(1) The first feature enabled users to change the weekdays on which goal-pursuing activities were planned. Users could deliberately edit goals and alter their plans by adding, changing, or deselecting weekdays. Autonomy affordance was signified by a calendar symbol, a heading reading "Days of the week", and switches for each weekday.

(2) Users were able to add an activity to pursue one of their already created goals on every given day. This second feature means that users could spontaneously add a goal-pursuing activity to a day on which no such activity had been planned or to expand their plan for the day by an additional activity for the same goal. Autonomy affordance was signified by a plus button which was positioned next to the date of each day in the goal journal tab of the app.

(3) Lastly, users could also move an activity to another day. Thus, they were able to carry out activities earlier or later than initially planned. Moving an activity was enabled for all activities that had not yet been logged. Autonomy affordance was signified by a calendar button displayed next to each activity.

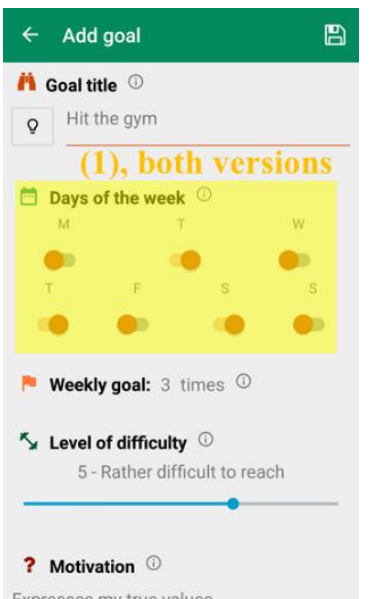

Figure 2. Screenshots of the app showing the three autonomy affordance signifiers

In the low autonomy affordance version (LAAV), we included the first two features and autonomy affordance signifiers. It is important to note that users had the autonomy to decide on their plans regarding 
their goal-pursuing activities anyways. The question here merely was in how far and how easily the app allowed for changing the plan to fit the behavior. We included these first two features and signifiers for each user to provide enough autonomy within the app as not to frustrate users and not to impair the usage of the app. However, changing the weekdays (first feature) required users to edit goals and modify their overall weekly plan for the goals in a rather cumbersome fashion. Also, spontaneously adding activities for existing goals (feature (2)) required users to mark the activities that were substituted by the spontaneously added ones as not done and admit failure.

Autonomy affordance was only genuinely enhanced to a level above minimum usability requirements by the third presented feature and signifier. Smoothly moving activities within the journal alleviated the struggles mentioned above and enabled the users to modify their plans freely. The enhanced autonomy affordance version (EAAV) consequently comprised all three presented features and signifiers. By providing the features and signifiers (1) and (2) in both versions and all three in the enhanced autonomy version as shown in Figure 2, we aimed to achieve the difficult task of balancing userfriendliness (providing a minimum level of autonomy affordance so that users stay with the app) and differentiation between versions (providing considerably enhanced autonomy affordance as compared to the low autonomy affordance version).

\subsection{Experiment Design and Procedures}

We placed the app in the Google Play Store and the Apple App Store and advertised it via email and various social media channels as well as a local newspaper and a local TV channel. The experiment ran from April to September 2017.

The app uploaded all data to a cloud service users were accurately informed about the intent and extent of data capture, upload, storage, and use and provided informed consent a priori. The data did not include any personally-identifying information. Starting with the first opening of the app, the upload was conducted every five days if a wireless network was available. If not, uploading via cellular data was delayed for three more attempts to spare data.

Either of the two app versions were randomly assigned after a user had installed the app. To sum up, we had two experimental treatments differing in the level of autonomy affordance (low autonomy affordance vs. enhanced autonomy affordance), random assignment of participants to treatments, and a between-subject comparison for the treatment variable enhanced autonomy affordance.

\subsection{Measurement of Constructs}

For the measurement of the constructs, we relied on log data that we acquired by tracking the goalsetting and goal-pursuing behavior of our field experiment's participants in the app.

\section{Table 1. Constructs measured via log data} and their operationalization and calculations

Construct Operationalization based on log data

Subjective An indication of the current emotional well-being state after marking an activity as done or not done on a scale of 5 emoji (ranging from 1 representing frustration to 5 representing elation)

\begin{tabular}{|c|c|}
\hline $\begin{array}{l}\text { Goal } \\
\text { perfor- } \\
\text { mance }\end{array}$ & $\begin{array}{l}\text { Number of goal-pursuing activities logged } \\
\text { as done (rather than not done) divided by } \\
\text { the sum of logged goal-pursuing activities; } \\
\text { values from zero (for users who logged all } \\
\text { activities as not done) to one (for users } \\
\text { who logged all activities as done) }\end{array}$ \\
\hline $\begin{array}{l}\text { Enhance- } \\
\text { ment of } \\
\text { autonomy } \\
\text { affordance }\end{array}$ & $\begin{array}{l}\text { Binary indicator on whether the user was } \\
\text { randomly assigned to the version of the } \\
\text { app with low }(0) \text { or enhanced (1) } \\
\text { autonomy affordance }\end{array}$ \\
\hline $\begin{array}{l}\text { Actuali- } \\
\text { zation of } \\
\text { autonomy } \\
\text { affordance }\end{array}$ & $\begin{array}{l}\text { Sum of changes of weekdays on which } \\
\text { goal-pursuing activities were planned for } \\
\text { (first feature), spontaneously added } \\
\text { activities (second feature), and moved } \\
\text { goal-pursuing activities (third feature, } \\
\text { available in the enhanced autonomy } \\
\text { affordance app version) divided by the } \\
\text { number of all activities in the observation } \\
\text { period; values from zero (for users who } \\
\text { did not actualize any autonomy } \\
\text { affordance) to infinity (for users who often } \\
\text { actualized autonomy affordance) }\end{array}$ \\
\hline $\begin{array}{l}\text { Motiva- } \\
\text { tion }\end{array}$ & $\begin{array}{l}\text { Selection of the most suitable motivation } \\
\text { for each goal from (English expressions } \\
\text { adapted from Reis et al. [27]): "Interesting } \\
\text { or enjoyable" (intrinsic), "Expresses my } \\
\text { true values" (identified), "Avoid anxiety } \\
\text { or guilt" (introjected), or "Forced by } \\
\text { external situation" (external) }\end{array}$ \\
\hline Difficulty & $\begin{array}{l}\text { Selection of the subjective difficulty of } \\
\text { reaching each goal on a 7-point Likert } \\
\text { scale with the anchors "1 - Very easy to } \\
\text { reach" and "7 - Very difficult to reach" }\end{array}$ \\
\hline
\end{tabular}

Creating, editing, and deleting goals, or logging, adding, and moving activities were logged. Based on this log data, the measures for the constructs could be calculated. Table 1 lists the nature of the collected log data and the definition of these measures. 
Although an emoji scale to measure subjective well-being has not been validated yet, multiple similar scales (e.g., smiley scales) have been used to capture subjective well-being directly after experiences [28]. Thus, we employ the feeling after logging indicated on a scale of five emoji as an unobtrusively and frequently surveyed measure of subjective well-being. Please see Figure 4 of the online appendix for an illustration. Its $\log$ data provides a rather continuous and unobtrusive basis for analyses as compared to, e.g., a longer multi-item survey scale once a week.

\section{Results}

\subsection{Descriptive Results}

For our analyses, we consider the users who logged activities as done or not done for at least two weeks. We choose this minimum observation period to avoid biases caused by short-term, uncommitted users. This gives us a sample of $\mathrm{n}=54$. Considering the 49 users who answered the optional question about their age, the mean age is 29 years with a minimum of 17 years and a maximum of 60 years. Considering the 48 users who answered the optional question about their gender, the share of female users is 58 percent.

The separation of the examined participants into users of the LAAV (34 users, also see "Provision" in Table 2) and the EAAV (20 users) distinguishes users according to the autonomy affordance provided to them. However, whether the mere availability of affordance entailed its actualization remains to be tested. A comparison of the autonomy affordance actualization measure (see Table 1) of users who were assigned the EAAV with users who were assigned the LAAV yields an observable difference. Users of the EAAV exhibited a mean actualization of 0.083 . In 74.9 percent of all times users of the EAAV actualized affordance, they used the third provided feature that was only available to them but not to the other group. Users of the LAAV showed a mean actualization of only 0.032. A Mann-Whitney-U test resulted in the rejection of the null-hypothesis that the two distributions of the actualization measure (20 EAAV users vs. 34 LAAV users) belong to the same population with a p-value of 0.012 . This is a first indicator of the positive association of the provision of enhanced autonomy affordance and its actualization and provides support for $\mathrm{H} 2$. As both the provision of enhanced autonomy affordance ( $\mathrm{H} 1$ and $\mathrm{H} 2)$ and its actualization ( $\mathrm{H} 3$ and $\mathrm{H} 4)$ were hypothesized to influence the presented constructs, the following presentations of descriptive results will distinguish the users both regarding autonomy affordance provision and autonomy affordance actualization (see "Actualization" in Table 2).

Table 2. Descriptive results

\begin{tabular}{lc|cc|cc} 
& & \multicolumn{2}{|c|}{ Provision } & \multicolumn{2}{|c}{ Actualization } \\
\cline { 2 - 7 } $\mathrm{n}$ & 54 & 20 & 34 & 26 & 28 \\
\hline $\begin{array}{l}\text { Mean affordance } \\
\text { actualization }\end{array}$ & 0.05 & 0.08 & 0.03 & 0.10 & 0.01 \\
\hline $\begin{array}{l}\text { Median number } \\
\text { of goals }\end{array}$ & 5 & 5 & 5 & 5 & 5 \\
\hline $\begin{array}{l}\text { Median number } \\
\text { of weekly } \\
\text { activities }\end{array}$ & 18 & 18 & 18.5 & 16.5 & 20 \\
$\begin{array}{l}\text { Median goal } \\
\text { difficulty }\end{array}$ & 4 & 4 & 4 & 4 & 4 \\
\hline $\begin{array}{l}\text { Median goal } \\
\text { motivation }\end{array}$ & 2 & 2 & 2 & 2 & 2.5 \\
\hline $\begin{array}{l}\text { Median logging } \\
\text { period (d) }\end{array}$ & 34 & 31 & 38 & 32 & 38 \\
\hline $\begin{array}{l}\text { Median share of } \\
\text { logged activities }\end{array}$ & 0.95 & 0.98 & 0.93 & 0.98 & 0.87 \\
\hline $\begin{array}{l}\text { Median goal } \\
\text { performance }\end{array}$ & 0.63 & 0.64 & 0.62 & 0.62 & 0.63 \\
\hline $\begin{array}{l}\text { Mean feeling } \\
\text { after logging }\end{array}$ & 3.51 & 3.62 & 3.44 & 3.55 & 3.47
\end{tabular}

The users entered between 1 and 19 goals with a median of 5 goals and 18 goal-pursuing activities per week. Typical goals include doing sports, eating more fruits or less sugar, studying a language, or getting up early. The median goal difficulty is 4 and the goals' median motivation is 2 (introjected). Users logged activities for periods up to 160 days, with a median of 34 days. A comparison using a Mantel-Haenszel test [22] which adapts the concept of survival curves for users of the two app versions suggests no significant group difference in the logging period (p-value of 0.249 ). Users logged between 4 and 100 percent of all activities, with a median of 95 percent. The observed goal performance is between 13 and 100 percent, with a median of 63 percent. I.e., across all users, 63 percent of planned activities logged by the users were done by them (according to self-report) while they failed to do 37 percent. The mean of the overall feeling after logging across all users is 3.51. Regarding activities logged as done, the feeling is 4.10. For activities logged as not done, the feeling after logging is 2.57 .

Table 2 displays the results of the descriptive analyses separated into an enhanced (E) and a low (L) subgroup based on autonomy affordance provision 
(Provision; based on random assignment) or autonomy affordance actualization (Actualization; based on a median split according to observed behavior).

\subsection{Hypotheses Testing with Path Analysis}

We hypothesized the enhanced provision of autonomy affordance to affect subjective well-being directly and positively (H1) as well as indirectly and positively via the mediator autonomy affordance actualization ( $\mathrm{H} 2$ and $\mathrm{H} 3)$. We expected autonomy affordance actualization to positively affect goal performance (H4), and goal performance to positively affect subjective well-being (H5). Additionally, we included the motivation and difficulty of goals as two important control variables.

We tested the hypothesized relationships by employing path analysis and utilizing the lavaan $\mathrm{R}$ package [29]. Path analysis allows for explaining relationships among directly measured, unidimensional constructs, both of which requirements are fulfilled given the operationalization of the examined constructs detailed in Table 1. Figure 3 depicts the results of the path analysis, including the estimated path coefficients and their significance level. H1, H2, H4, and H5 were supported while we found no support for $\mathrm{H} 3$.

Following Little and Kline [19], we conducted a Chi-square test and calculated the fit indices root mean square error of approximation (RMSEA), comparative fit index (CFI), and square root mean residual (SRMR) to assess our model. The Chi-square test statistic over the degrees of freedom results in an acceptable value of 0.804 [9], whereas the p-value of 0.045 hints at suboptimal model fit [2]. The RMSEA of our model is 0.130 , with values smaller than 0.07 indicating good model fit [33]. The CFI indicates a satisfactory model fit if higher than 0.90 [13] and amounts to 0.877 for our model. The SRMR should show values smaller than 0.08 [13] and is 0.077 for our model. Overall, we conclude that our model exhibits a moderate fit and include a discussion of this topic in the limitation section. The $\mathrm{R}^{2}$ values for subjective well-being, goal performance, and autonomy affordance actualization are $0.560,0.277$, and 0.108 , respectively.

\section{Discussion}

We hypothesized the provision of enhanced autonomy affordance to directly and positively influence subjective well-being $(\mathrm{H} 1)$, a relation that was found significant. This implies that the mere provision of enhanced autonomy affordance improved the users' feelings, even when controlling for the effects of actualized autonomy affordance and goal performance (users generally felt better after logging done than after logging not done). Hence, the provision of enhanced autonomy affordance lead to improved subjective well-being without it being actualized. It is important to note that this applies to the measurement of subjective well-being with a smiley scale as laid out in the methodology section and needs to be verified with other measures of subjective well-being in the future.

The provision of enhanced autonomy affordance was positively related to its actualization (H2). Users who were provided with an additional feature that allowed them to adapt the plans for their goal-directed behavior and who were presented with more autonomy affordance signifiers did indeed exercise the additionally provided options more often and actualized autonomy affordance to a greater extent.

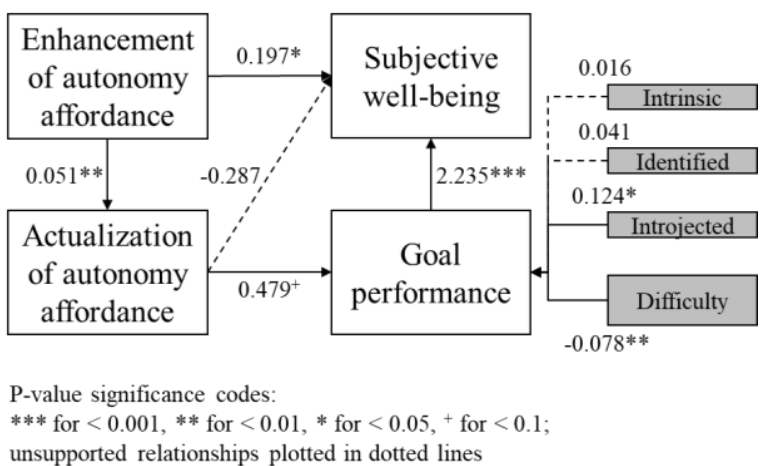

Figure 3. Results of path analysis including path coefficients

The exercise of autonomy affordance, however, did not translate directly into higher degrees of subjective well-being as postulated in H3. This might indicate that the provision of enhanced autonomy affordance was sufficient to increase the users' subjective well-being. Its actualization might not be necessary to reap the benefits of a more autonomous feeling of the users on subjective well-being.

The actualization of autonomy affordance did, however, improve goal performance (H4). The actualization might have enabled users to react to unforeseen restrictions and bypass them, resulting in a higher goal performance due to the adaptability of their goal-pursuing behavior to their circumstances.

Lastly, subjective well-being was significantly and positively affected by goal performance (H5). The better the users of the app performed, the better they felt after logging activities as done or failed. This confirmation of $\mathrm{H} 3$ is intuitive and in line with a larger body of literature $[15,16]$.

Therefore, we answer our research question as follows: The provision of enhanced autonomy 
affordance directly increases the user's subjective well-being. Also, goal performance is positively affected as enhanced autonomy affordance increases its actualization, which in turn increases goal performance. The positive effect of goal performance on subjective well-being, in turn, leads to an indirect effect of the provision of enhanced autonomy affordance on the users' subjective well-being. Interestingly, the mere provision of enhanced autonomy affordance seems to be sufficient to increase the user's subjective well-being, while the increase of goal performance requires affordance actualization.

The current work has three main implications that relate to our contribution to the underlying literature, the research instrument, and the design of self-tracking IS. First of all, our hypotheses aggregate findings from various areas of IS research and psychology, such as well-being, motivation, and personality. Although only four of the five hypotheses are supported empirically, our results support the positive effects of the provision of enhanced autonomy affordance on its actualization, goal performance, and subjective wellbeing. Thus, our results strengthen the findings of Self-determination Theory regarding the relationship between autonomy and well-being presented in the theoretical background and hypotheses development sections. More importantly, we demonstrate the underlying theory's applicability in the context of the design of IS for self-tracking goal-directed behavior. To the best of our knowledge, this study is the first to argue and empirically demonstrate these effects in this context. Hence, our study contributes to the body of design knowledge in positive computing and selftracking IS. Besides, we have shown that the effect of autonomy might not originate from its actualization, but that its offering might already be sufficient. We add to Affordance Theory as we empirically observed that the mere provision of affordance can affect the users' subjective well-being while self-tracking goals.

Second, we created a measurement instrument by developing a mobile application that represents an easy way to capture the entirety of our model's constructs. Its design may facilitate similar research endeavors in the future. Once the app had been developed and distributed, it reliably and continuously captured empirical data and delivered it to our research team. The maintenance effort was limited to minor updates and the data analysis could be automated. Nevertheless, we recommend several refinements of the app's design before further applying it as a measurement instrument. Users should be able to enter goals that do not necessarily have at least one goalpursuing activity a week. The app should allow goals with differing activity-rhythms as well. Next, users should be able to pass on goal-pursuing activities and not be restricted to either marking them as done or failed. This way, the app could implement pauses in the goal-directed behavior due to illness or vacation, track the users' activities more accurately, and afford the users with additional autonomy. The proposed refinements should improve the usability of the app, the amount of time for which users stay with the app, and the quality of the captured data.

Third, based on the results, we conclude that any self-tracking IS which is intended to further the success and well-being of its users while they work towards their goals should implement autonomysupportive functions such as providing choices regarding goal-directed behavior. Furthermore, we argue that the presented considerations on the influence of the provision of enhanced autonomy affordance on subjective well-being can be transferred to organizational contexts like universities, schools, and companies as well. In these settings, usually, both the goals and the IS that is used to track the goal progress are predetermined by the organization. In contrast to self-tracking goals in the private, individual context where users freely choose the IS and the goals themselves, the behavior of some organizational users might thus be significantly less autonomously regulated. This highlights the need for autonomysupportive functions and stresses their potential to increase the well-being of the members of an organization. These effects are, in turn, likely to translate into benefits of monetary or reputational nature for the organization.

\section{Conclusion}

\subsection{Limitations}

The current work's research process and results have limitations which highlight the need for further research about the interconnections of the provision of enhanced autonomy affordance, goal performance, and well-being in self-tracking IS. First of all, although 54 individuals took part in the study for at least 14 days, the sample size is still quite small and the achieved empirical model fit is not optimal, which considerably impairs generalizability. However, we do not focus on the interpretation of the exact values of the coefficients. Still, we take significant results as the first confirmation of both the relationships between the dependent and the independent variables and its direction. Therefore, to verify our results, the study should be rerun after the refinements to the app that were proposed in the discussion section to achieve a larger sample size.

Second, the data that was collected by the app originates from self-reports by the users. Furthermore, 
according to interviews with several users who used the option to provide feedback, which was given during the experiment, their interpretations of not logging an activity differed. For some users, it had the equivalent meaning of logging an activity as not done. For others, it meant that they had simply forgotten to $\log$ and that the share of done and not done activities, if they had logged them, would have been similar to that of the days or weeks before.

Third, the installation and subsequent usage of a self-tracking app represent a form of self-selection. Not every individual knows about habit trackers, has access to them, or is sufficiently convinced of their usefulness to install and use them. Further research needs to develop an understanding of who the users of self-tracking IS are and why they track their behavior. It should be analyzed whether there are differences in personality, behavioral patterns, or other characteristics in comparison to non-users. Future studies should as well build on works like that of Gimpel et al. [10] to determine which motivations lead users to engage in self-tracking. Similarly, it is yet unclear whether there are users who benefit more or less from the provision of autonomy affordance.

\subsection{Summary}

The current work examined the effects of the provision of enhanced autonomy affordance on its actualization, goal performance, and well-being in the context of self-tracking IS for goal-directed behavior. Our theoretical development leverages Selfdetermination Theory and Affordance Theory and relates explicitly to the literature on self-tracking and positive computing. The theoretical hypotheses were mostly empirically supported in a field experiment. The empirical data was gathered via a mobile application that was developed for this purpose. The app collected self-tracking data about the goaldirected behavior of 54 participants who used it for a median observation period of 34 days. The results represent a first indication that self-tracking IS should afford autonomy to further both their users' goal performance and well-being.

Overall, our research and its further development contributes to positive computing and self-tracking IS and informs designers of self-tracking systems on the benefits of affording users with autonomy rather than telling them to defeat their weaker self and stick to their pre-determined plans regardless of the circumstances. Furthermore, it shows that in this context, merely affording more autonomy can have positive effects above and beyond the positive effects of the actualization of affordance.
With this, we hopefully supported users, despite exhausting working days, in reaching their goals and at the same time increase their well-being.

\section{References}

[1] Akbari, E., A. Pilot, and P. Robert-Jan Simons, "Autonomy, competence, and relatedness in foreign language learning through Facebook", Computers in Human Behavior, 48, 2015, pp. 126-134.

[2] Barrett, P., "Structural equation modelling: Adjudging model fit", Personality and Individual Differences, 42(5), 2007, pp. 815-824.

[3] Boersma, S.N., S. Maes, K. Joekes, and E. Dusseldorp, "Goal processes in relation to goal attainment: Predicting health-related quality of life in myocardial infarction patients", Journal of health psychology, 11(6), 2006, pp. 927-941.

[4] Botella, C., G. Riva, A. Gaggioli, B.K. Wiederhold, M. Alcaniz, and R.M. Banos, "The Present and Future of Positive Technologies", Cyberpsychology, behavior and social networking, 15(2), 2012, pp. 78-84.

[5] Brunstein, J.C., "Personal Goals and Subjective WellBeing: A Longitudinal Study", Journal of personality and social psychology, 65(5), 1993, pp. 1061-1070.

[6] Buchwald, A., A. Letner, N. Urbach, and M.v. EntreßFürsteneck, "Insights into Personal ICT Use: Understanding continuance and Discontinuance of Wearable Self-tracking Devices", in 26th European Conference on Information Systems (ECIS). 2018.

[7] Diener, E., R.E. Lucas, and C.N. Scollon, "Beyond the hedonic treadmill: revising the adaptation theory of well-being", The American psychologist, 61(4), 2006, pp. 305-314.

[8] Elliot, A.J. and D. Niesta, "Goals in the Context of the Hierarchical Model of Approach-Avoidance Motivation", in The Psychology of Goals, G.B. Moskowitz and H. Grant, Editors. 2009. Guilford Press: New York, New York, The United States of America.

[9] Gefen, D., D. Straub, and M.-C. Boudreau, "Structural Equation Modeling and Regression: Guidelines for Research Practice", Communications of the Association for Information Systems, 4, 2000.

[10] Gimpel, H., M. Nißen, and R.A. Görlitz, "Quantifying the Quantified Self: A Study on the Motivations of Patients to Track Their Own Health", in Thirty Fourth International Conference on Information Systems 2013. 2013.

[11] Hall, M., Detecting Well-being in Digital Communities: An Interdisciplinary Engineering Approach for its Indicators, Karlsruhe, 2015.

[12] Harkin, B., T.L. Webb, B.P.I. Chang, A. Prestwich, M. Conner, I. Kellar, Y. Benn, and P. Sheeran, "Does monitoring goal progress promote goal attainment? A meta-analysis of the experimental evidence", Psychological Bulletin, 142(2), 2016, pp. 198-229.

[13] Hu, L.-t. and P.M. Bentler, "Cutoff criteria for fit indexes in covariance structure analysis: Conventional criteria versus new alternatives", Structural Equation 
Modeling: A Multidisciplinary Journal, 6(1), 1999, pp. 1-55.

[14] Huppert, F.A. and T.T.C. So, What percentage of people in Europe are flourishing and what characterises them?: Prepared for the OECD/ISQOLS meeting "Measuring subjective well-being: an opportunity for NSOs?" in Florence - July 23/24, 2009, University of Cambridge, The Well-being Institute, 2009.

[15] Klug, H.J.P. and G.W. Maier, "Linking Goal Progress and Subjective Well-Being: A Meta-analysis", Journal of Happiness Studies, 16(1), 2015, pp. 37-65.

[16] Koestner, R., N. Lekes, T.A. Powers, and E. Chicoine, "Attaining personal goals: Self-concordance plus implementation intentions equals success", Journal of personality and social psychology, 83(1), 2002, pp. 231-244.

[17] Koestner, R., N. Otis, T.A. Powers, L. Pelletier, and H. Gagnon, "Autonomous motivation, controlled motivation, and goal progress", Journal of personality, 76(5), 2008, pp. 1201-1230.

[18] Krueger, A.B. and D.A. Schkade, "The Reliability of Subjective Well-Being Measures", Journal of public economics, 92(8-9), 2008, pp. 1833-1845.

[19] Little, T.D. and R.B. Kline, eds., Principles and practice of structural equation modeling, The Guilford Press, New York, London, 2016.

[20] Lupton, D., "Self-tracking cultures: towards a sociology of personal informatics", in Proceedings of the 26th Australian Computer-Human Interaction Conference on Designing Futures: the Future of Design, Sydney, New South Wales, Australia, 2 - 5 December. 2014.

[21] Lupton, D., Self-tracking Modes: Reflexive SelfMonitoring and Data Practices: Paper for the 'Imminent Citizenships: Personhood and Identity Politics in the Informatic Age' workshop, 27 August 2014, ANU, Canberra, University of Canberra, Faculty of Arts \& Design, News \& Media Research Centre, 27 August 2014.

[22] Mantel, N. and W. Haenszel, "Statistical Aspects of the Analysis of Data From Retrospective Studies of Disease", JNCI: Journal of the National Cancer Institute, 22(4), 1959, pp. 719-748.

[23] Markus, M.L. and M. Silver, "A Foundation for the Study of IT Effects: A New Look at DeSanctis and Poole's Concepts of Structural Features and Spirit", Journal of the Association for Information Systems, 9(10), 2008, pp. 609-632.

[24] Norman, D.A., The design of everyday things, Basic Books, New York New York, 2013.

[25] Patall, E.A., H. Cooper, and J.C. Robinson, "The effects of choice on intrinsic motivation and related outcomes: a meta-analysis of research findings", Psychological Bulletin, 134(2), 2008, pp. 270-300.

[26] Pinder, C., J. Vermeulen, B.R. Cowan, and R. Beale, "Digital Behaviour Change Interventions to Break and Form Habits", ACM Transactions on Computer-Human Interaction, 25(3), 2018, pp. 1-66.

[27] Reis, H.T., K.M. Sheldon, S.L. Gable, J. Roscoe, and R.M. Ryan, "Daily Well-Being: The Role of Autonomy,
Competence, and Relatedness", Personality and Social Psychology Bulletin, 26(4), 2000, pp. 419-435.

[28] Ross, T., A. Burris, L. Oliveira, B. Arnott, and V. Araujo-Soares, "A Feasibility Study of the Effect of Phone-Based Feedback of Other Commuters' Subjective Experiences on Driver Intentions to Change", in Design, User Experience, and Usability: Design Discourse, A. Marcus, Editor. 2015. Springer International Publishing: Cham.

[29] Rosseel, Y., "Lavaan: An R package for structural equation modeling and more. Version 0.5-12 (BETA)", Journal of statistical software, 48(2), 2012, pp. 1-36.

[30] Ryan, R.M. and E.L. Deci, "Self-Determination Theory and the Facilitation of Intrinsic Motivation, Social Development, and Well-Being", American Psychologist, 55(1), 2000, pp. 68-78.

[31] Ryan, R.M. and E.L. Deci, "On Happiness and Human Potentials: A Review of Research on Hedonic and Eudaimonic Well-Being", Annual Review of Psychology, 52, 2001, pp. 144-166.

[32] Steca, P., D. Monzani, A. Greco, M. D’Addario, E. Cappelletti, and L. Pancani, "The Effects of Short-Term Personal Goals on Subjective Well-Being", Journal of Happiness Studies, 17(4), 2016, pp. 1435-1450.

[33] Steiger, J.H., "Understanding the limitations of global fit assessment in structural equation modeling", Personality and Individual Differences, 42(5), 2007, pp. 893-898.

[34] Strong, D., O. Volkoff, S. Johnson, L. Pelletier, B. Tulu, I. Bar-On, J. Trudel, and L. Garber, "A Theory of Organization-EHR Affordance Actualization", Journal of the Association for Information Systems, 15(2), 2014, pp. 53-85.

[35] Vansteenkiste, M., J. Simons, W. Lens, K.M. Sheldon, and E.L. Deci, "Motivating learning, performance, and persistence: The synergistic effects of intrinsic goal contents and autonomy-supportive contexts", Journal of personality and social psychology, 87(2), 2004, pp. 246-260.

[36] Walker, M.J., Hype Cycle for Emerging Technologies, 2017, Gartner, Inc., 2017.

[37] Wood, W. and D.T. Neal, "A new look at habits and the habit-goal interface", Psychological Review, 114(4), 2007, pp. 843-863.

[38] Zhao, J., B. Freeman, and M. Li, "Can Mobile Phone Apps Influence People's Health Behavior Change? An Evidence Review", Journal of medical Internet research, 18(11), 2016, e287. 